\title{
O Coming Out de Gays no Seio Familiar: Relatos de experiência
}

\author{
The Coming Out of Gays in the Family Breast: Experience reports \\ La Coming Out de los Gays en el Mama Familiar: Relatos de experiência
}

Lucas Souza Almeida de Araujo ORCID: https://orcid.org/0000-0001-5723-6725 Faculdade Anísio Teixeira, Brasil E-mail: lucas.araujx@hotmail.com

Joyce Yara dos Santos Machado ORCID: https://orcid.org/0000-0003-4570-424X Faculdade Anísio Teixeira, Brasil

E-mail: joyce_yara_santos@hotmail.com Rafaella Souza de Lima ORCID: https://orcid.org/0000-0002-6006-3578 Faculdade Anísio Teixeira, Brasil E-mail: raffahsherry123@gmail.com

Maria Emília Cirqueira Silva

ORCID: https://orcid.org/0000-0002-8556-482X Faculdade Anísio Teixeira, Brasil

E-mail: emiliacirqueira@gmail.com

Guthierre Almeida Portugal

ORCID: https://orcid.org/0000-0003-1779-4997

Universidade Estadual de Feira de Santana, Brasil E-mail: guthierresamu@gmail.com

Bruna Matos Santos Dantas

ORCID: https://orcid.org/0000-0002-2829-8422

Universidade Estadual de Feira de Santana, Brasil E-mail: brunamatos.dantas@gmail.com

Magno Conceição das Mercês

ORCID: https://orcid.org/0000-0003-3493-8606

Universidade do Estado da Bahia, Brasil E-mail: magnomerces@hotmail.com

Caroline Santos Silva

ORCID: https://orcid.org/0000-0001-5321-3796

Universidade Estadual de Feira de Santana, Brasil E-mail: s.carolinne5@gmail.com

Luiz Alberto da Silva Lima

ORCID: https://orcid.org/0000-0003-0804-2590

Universidade do Estado da Bahia, Brasil E-mail: laslima@uneb.br

Julita Maria Freitas Coelho

ORCID: https://orcid.org/0000-0002-9520-5177

Instituto Federal da Bahia, Brasil

E-mail: julitamaria@gmail.com

Valterney de Oliveira Morais

ORCID: https://orcid.org/0000-0002-7119-5584

Universidade Estadual de Feira de Santana, Brasil

E-mail: valterneyoliveiramorais@gmail.com

\section{Resumo}

No processo de descoberta e revelação da orientação sexual, o termo outness é utilizado para se referir ao ato de se reconhecer homossexual, enquanto o termo coming out é sinônimo do que é conhecido como "sair do armário" ou assumir-se homossexual perante a sociedade e a família. Nesse contexto, a revelação da orientação sexual pode vir a se manifestar como um problema nas relações pessoais, sobretudo no seio familiar . Trata-se de um estudo de caráter qualitativo, descritivo e exploratório, do tipo de relato de experiência, tendo como estratégia de acesso às fontes o método Snowball. Para identificação dos participantes, foi solicitado a um homem cis gay, denominado de "Semente", que nos indicasse dois homens também cis gays, que tiveram experiências diferentes na assunção da sua sexualidade no seio familiar. Obtiveram-se dois relatos identificados como "Relato 1 - Azul" e "Relato 2 - Vermelho". Quanto à assunção da sua sexulidade, Azul relatou que não interferiu muito na relação com a sua família. E que a relação sempre foi de autoexclusão, sendo excluido também pelos familiares. Vermelho diz que o processo de assunção da sua sexualidade não interferiu na sua relação com familiares, e que no ínicio, houve um período de adaptação e construção 
de um respeito mútuo entre ele e sua mãe e com a irmã e o irmão, nada mudou. O presente estudo poderá embasar discussões relacionadas à influência das reações e vínculos familiares no processo de descoberta da orientação sexual do indivíduo, bem como, no seu comportamento perante a família e a sociedade.

Palavras-chave: Homossexual; Homossexualidade masculina; Relações familiares; Assunção da sexualidade.

\begin{abstract}
In the process of discovering and revealing sexual orientation, the term outness is used to refer to the act of recognizing oneself as a homosexual, while the term coming out is synonymous with what is known as "coming out of the closet" or coming out as a homosexual in society and the family. In this context, the disclosure of sexual orientation may come to manifest as a problem in personal relationships, especially within the family. This is a qualitative, descriptive and exploratory study, of the type of experience report, using the Snowball method as a strategy for accessing the sources. To identify the participants, a cis gay man, called "Seed", was asked to indicate two men also cis gay, who had different experiences in the assumption of their sexuality within the family. Two reports were obtained, identified as "Report 1 - Blue" and "Report 2 - Red". As for the assumption of her sexuality, Azul reported that she did not interfere much in her relationship with her family. And that the relationship has always been one of self-exclusion, being excluded by family members as well. Vermelho says that the process of assuming his sexuality did not interfere in his relationship with family members, and that in the beginning, there was a period of adaptation and construction of mutual respect between him and his mother and with his sister and brother, nothing changed. This study may support discussions related to the influence of family reactions and bonds in the process of discovering the individual's sexual orientation, as well as in their behavior towards the family and society.
\end{abstract}

Keywords: Homosexual; Male homosexuality; Family relationships; Assumption of sexuality.

\title{
Resumen
}

En el proceso de descubrir y revelar la orientación sexual, el término outness se utiliza para referirse al acto de reconocerse a sí mismo como homosexual, mientras que el término coming out es sinónimo de lo que se conoce como "salir del armario". En este contexto, la revelación de la orientación sexual puede llegar a manifestarse como un problema en las relaciones personales, especialmente dentro de la familia. Se trata de un estudio cualitativo, descriptivo y exploratorio, del tipo de relato de experiencia, utilizando el método Snowball como estrategia de acceso a las fuentes. Para identificar a los participantes, se le pidió a un hombre cis gay, llamado "Semilla", que indicara a dos hombres también cis gay, que tenían diferentes experiencias en la asunción de su sexualidad dentro de la familia. Se obtuvieron dos informes, identificados como "Informe 1 - Azul" e "Informe 2 - Rojo". En cuanto a la asunción de su sexualidad, Azul informó que no interfirió mucho en su relación con su familia. Y que la relación fue siempre de autoexclusión, siendo excluidos también por familiares. Vermelho dice que el proceso de asumir su sexualidad no interfirió en su relación con los familiares, y que en un inicio hubo un período de adaptación y construcción de respeto mutuo entre él y su madre y con su hermana y hermano, nada cambió. . Este estudio puede apoyar discusiones relacionadas con la influencia de las reacciones y vínculos familiares en el proceso de descubrimiento de la orientación sexual del individuo, así como en su comportamiento hacia la familia y la sociedad.

Palabras clave: Homosexual; Homosexualidad masculina; Relaciones familiares; Asunción de la sexualidad.

\section{Introdução}

Os conhecimentos acerca da sexualidade humana são apresentados como frutos de uma construção sócio-histórica, podendo ser compreendida como uma condição inerente a sua existência. Cada sociedade, de acordo com sua cultura e tempo, consolidou como verdade discursos e significados sobre a sexualidade, tornando-a alvo de vigilância e punição, alcançando assim, a padronização do comportamento sexual (Esperança; Silva; Neves, 2015).

Segundo Dias (2000), a sexualidade une-se convenientemente a condição humana, sendo ela um direito essencial desde seu nascimento. É um direito natural e imprescritível dos indivíduos, que deve ser assegurado para que cada ser tenha respeito ao exercer sua sexualidade, incluindo assim, a liberdade sexual e a liberdade da livre orientação sexual, sendo a privação da mesma equivalente a negação de quaisquer outros direitos constitucionais.

Por sua vez, Carrara et al. (2009) referem-se a sexualidade como às construções culturais sobre os prazeres e as interações sociais e corporais que compreendem desde o erotismo, o desejo e o afeto, até noções relativas à saúde, à reprodução, ao uso de tecnologias e ao exercício do poder na sociedade. Nesse sentido, Toneli (2012) apontou que as hipóteses geradas sobre o que é sexualidade perpetram sobre sua construção social e histórica, que indicam a existência da relação de poder. A sexualidade é o que o indivíduo identifica em si e condiz com seu prazer e fantasias, sendo essa sua particularidade e identidade, 
tornando-a o ponto base da identidade e do ser no mundo.

Considerando amplamente todos os conceitos, relatos, descrições e hipóteses quanto a sexualidade e sua relevância, a família é vista como o maior alicerce para que o sujeito possa revelar sua sexualidade perante si mesmo e a sociedade. No entanto os sujeitos podem ficar mais expostos a experiências de preconceitos e homofobia, que podem se associar a problemas de saúde mental e física, em contrapartida a ocultação da mesma pode ocasionar riscos similares (Nascimento et al, 2018).

Nesse sentido, ao se aprofundar no estudo da homossexualidade, Bourdieu (2010) focou nos movimentos sociais que empregavam os termos "lésbica" e "gay", e analisou a dificuldade de expressar as definições do movimento e da homossexualidade. Assim, indagou se seria necessário considerar as práticas sexuais, frequência a certos lugares ou o estilo de vida para que alguém seja definido ${ }^{1}$ como homossexual.

Sabe-se que o termo homossexual fora utilizado com a intenção de categorizar e dividir entre espécies, pessoas que se relacionavam com outras do mesmo sexo, apontou Foucault (1979). Por sua vez, Carrara e Helborn (2009) e Martins et al. (2010) designam como homossexual a pessoa que se sente atraída sexual, emocional ou esteticamente por pessoas do mesmo sexo/gênero. Assim, o termo pode se referir a homossexuais femininas - lésbicas, ou homossexuais masculinos - gays.

No processo de descoberta e revelação da orientação sexual, Maffesoli (2007) e Miskolci (2015) utilizam os termos outness, referindo-se ao assumir-se homossexual para si mesmo e coming out referindo ao processo conhecido como "sair do armário" ou, assumir-se perante a família e a sociedade. Jovens que decidem pelo coming out são comumente tomados por frustrações, devido ao despreparo da família para tornar o ambiente acolhedor como é esperado além de, muitas vezes, serem responsáveis por reproduzir situações de violência e intolerância (Nascimento, 2018).

O processo de revelação da orientação sexual pode vir a se manifestar como um problema nas relações interpessoais, sobretudo no seio familiar. Considerando os estudos da atualidade, é necessário ressaltar que mesmo havendo produção científica quanto a temática homossexual, poucos são os estudos no tocante a percepção dos sujeitos acerca da sua sexualidade (Maffesoli, 2007; Miskolci, 2015). Segundo Mota et al (2011), a família é uma integração básica da sociedade formada por indivíduos com ancestrais em comum ou ligados por laços afetivos, que pode ser também considerada como um conjugado invisível de exigências funcionais que forma a interação dos membros da mesma, considerando- a do mesmo modo como um sistema, que opera através de padrões transacionais.

Ou seja, o meio familiar propicia a sustentação da afetividade e também desempenha um papel decisivo na educação de seus membros, pois é nela que são aprendidos os valores éticos e humanitários necessários para se viver em sociedade. Muitas vezes, os pais não sabem como agir diante das demonstrações da sexualidade de seus filhos, porque não é tarefa fácil aceitar e entender a maneira de pensar dos jovens. É preciso rever preconceitos e estereótipos, entender as diferenças de idéias, uma vez que o crescimento dos filhos pode gerar conflitos e tensão familiar (Nolte et al, 2005).

Discorrer espontaneamente sobre homossexualidade dentro do ambiente familiar é imprescindível para se trabalhar a temática junto com a criação de medidas para permitir o desenvolvimento pessoal de jovens em plena descoberta de suas sexualidades. Ou seja, favorecer sua manifestação de forma livre, sem sofrer violências ou medos por isso. O núcleo familiar, portanto, representa uma das bases na formação de indivíduos responsáveis para o convívio harmônico em sociedade (Zagury, 2002).

Além disso, a família se faz importante não apenas diante do coming out, mas de um modo geral na vida dos indivíduos. Mas no que tange a revelação da orientação sexual, a família pode ser acolhedora ou não perante o ente que revela, acarretando uma série de fatores na vida dos envolvidos. Pode ser que, ao ter uma família acolhedora, o indivíduo tenha mais recursos para ter uma melhor qualidade de vida, ou quando não acolhido, pode recorrer às drogas e outros meios ilícitos para ao menos tentar

${ }^{1}$ Por se tratar de um estudo realizado apenas com homens cis, optou-se por não fazer uso de uma linguagem neutra. 
vivenciar essa fase de modo menos doloroso (Costa et al, 2010).

Partindo dos fatos mencionados anteriormente, objetivou-se relatar as experiências vividas por dois homens cis gays no processo de assunção da sua sexualidade para família.

\section{Materiais e Métodos}

Trata-se de um estudo de campo, de caráter qualitativo, descritivo e exploratório, do tipo relato de experiência, realizado em Feira de Santana - BA, no período de agosto a novembro de 2020.

Foram adotados como critérios de inclusão para participação nessa investigação: ser homem, cis, gay, maior de 18 anos, com família ciente da sua orientação sexual, residir no municipio de Feira de Santana e ter preenchido o Termo de Consentimento Livre e Esclarecido (TCLE), permitindo a utilização dos seus relatos.

A estratégia de seleção de participantes empregada foi o método Snowball (Dewes, 2013). Para identificação dos participantes do estudo, foi solicitado a um homem cis gay, denominado de "Semente", que indicasse dois homens cis gays, que tivessem passado por experiências diferentes na assunção da sua sexualidade no seio familiar.

O convite para participação no estudo se deu por meio de uma conversa através do whatsapp, quando foi feita uma explicação minunciosa do trabalho e seu devido objetivo. Ou seja, nessa ocasião ocorreu o processo de obtenção do consentimento para participação no estudo, incluindo a apresentação do TCLE. Foi elucidada aos dois participantes a possibilidade de que esse estudo possa contribuir com informações relevantes acerca da população gay, com ênfase no comingout.

Após leitura desse termo, o qual foi elaborado e disponibilizado com o emprego da ferramenta Google Forms, as dúvidas dos particpantes foram prontamente sanadas pelos pesquisadores. Em seguida, a manifestação de interesse em fazer parte da pesquisa foi registrada com o envio da anuência de cada um deles. Foi realizado um novo contato para agendamento de uma vídeo-conferência a ser realizada pela plataforma Google Meet, devido as recomendações sanitarias de distanciamento social por conta da pandemia de COVID-19.

Os relatos ocorreram em dia e horário escolhido por cada relator, segundo sua preferência para garantia do anonimato e preservação do seu conforto. Os mesmos foram individualmente coletados, gravados e posteriormente foram transcritos na integra para compor o artigo.

Esta pesquisa respeitou a Resolução 510 de 07 de abril de 2016, que dispõe sobre a realização de pesquisas com seres humanos e foi aporvada analisada pelo Comitê de Ética em Pesquisa da Faculdade Anísio Teixeira (CEP/FAT), no formato de relato de caso (CAAE: 48781821.8.0000.5631).

\section{Resultados}

Os principais achados desse estudo partiram dos dois relatos obtidos, os quais foram identificados como "Relato 01 Azul" e "Relato 02 - Vermelho", garantindo assim o anonimato dos participantes.

\section{Relato 01 - Azul}

Participante intitulado de Azul, 18 anos, negro, possui renda familiar baseada em um salário mínimo e aluguel de um imóvel. Relatou que seu vínculo religioso se deu por influencia da mãe que se considera católica, tendo frequentado, quando criança, a catequese por algumas semanas. No entanto, se desvinculou da igreja católica e passou a frequentar a igreja evangélica ficando assim, ciente do que era esse mundo, o que eles abominavam e era errado pra eles. À medida que crescia Azul permanecia frequentando a igreja, tendo ainda mais noção do que "era errado" e, consequentemente, era impactado negativamente por conta 
disso.

A partir dos 14 anos, o mesmo percebeu ser gay, constatando sua atração por meninos, entendendo que sempre se sentiu um tanto diferente, não conseguindo gostar de meninas e nem sentir atração por elas. Azul, inclusive relata que possuia atração por um amigo de infância, e ficava pensando coisas do tipo: "não posso me sentir assim porque eu vou pro inferno, é errado, as pessoas não gostam disso, ninguém gosta disso, eu não posso ser assim”. Nisso, foi se isolando cada vez mais e ficando pior consigo mesmo, se condenando.

Azul relatou que com 14 anos sendo bem exato, descobriu sua orientação sexual, mas, antes disso, já ouvia conversas entre sua família que davam a entender que esta já tinha idéia de que ele era gay. A descorbeta da sua orientação pela família se deu de modo natural, melhor do que ele esperava, por parte dos membros familiares, uma vez que, já tinham LGBTs na família, uma tia, um tio e um primo. Porém, a reação de sua mãe foi um tanto diferente, fazendo com que ele acreditasse ser mais difícil para mãe aceitar do que para família.

Em 2018, com 17 anos, ele pontua que estava se sentindo saturado com tudo e em uma conversa com uma amiga disse o seguinte: "velho eu não posso conversar isso com minha mãe, ela não pode saber isso, eu vou sei lá namorar e casar com uma menina, porque ela não merece esse desgosto e tudo mais". O mesmo percebeu a partir desse momento que isso não seria possível, ele não conseguiria gostar, não conseguiria se atrair por meninas e isso o machucava. Nesse período, o mesmo já tinha algumas atitudes que prefiriu omitir.

A situação interferia diretamente em sua vida, chegando o momento em que sentiu a necessidade de ir até sua mãe e falar: "mãe olha a gente precisa conversar, eu sou gay", sendo o mais direto possivel, apesar da dificuldade. Nesse momento, Azul diz que sua mãe estava com o semblante normal, até um tanto feliz, mas, assim que ele contou aquilo decaiu, se tornando um olhar de decepção, mas sem sinal algum de surpresa.

Passado algum tempo, em uma conversa com sua mãe, ela diz: "que aceitava porque não tinha como", e proseguiu dizendo que "isso era coisa do demônio e era maldição de família". E que, "não poderia fazer nada", diante da situação, Azul diz ter ficado sem reação. Não esperava aquela conversa, ao menos não naquele momento.

Quanto à assunção de sua sexualidade, Azul relatou que não interferiu muito na relação com a sua família. E que a relação sempre foi um tanto, por parte dele, de autoexclusão, sendo excluido também pelos familiares. O mesmo diz que gostava de ficar mais recluso e sempre foi incompreendido por eles e assim, depois que contou tudo, ele já sentiu mais liberdade para conversar com qualquer pessoa, sobre qualquer coisa desde que ele quisesse.

Atualmente a relação com todos é tranquila, sendo que Azul, opta por se manter um pouco distante, visto que sempre intercorrem conversas e comentários dos quais não gosta. Apesar disso, busca aprender a lidar, não expõe suas convicções como anteriormente, a menos que peçam que o faça. Não frequenta reuniões de família, pois não se sente bem, e opta em ficar fazendo outras atividades. No entanto, não considera que seja uma relação horrível, já que se forem falar sobre qualquer outra coisa que não envolva isso o diálogo segue naturalmente.

Por fim, Azul relata que realmente prefere se distanciar um pouco da família e que a relação com a mãe, que é com quem convíve, não é das melhores, porém não é a pior possível. Diz que respeitam o espaço um do outro, conversam poucas vezes e que não há troca de farpas ou uma relação de ódio ou algo do tipo.

\section{Relato 02 - Vermelho}

Vermelho, 23 anos, autodeclarado preto, com renda familiar de três salários mínimos, relata ser evangélico afastado, com mãe e irmã Pastora e Levita respectivamente, irmão sem vínculo religioso e demais pessoas da família disribuídas entre católicos e candomblecistas. Acredita que, desde os 07 anos, já tinha ciência de que não sentia atração pelo sexo oposto e sim pelo mesmo sexo que o seu. 
Diz que, quando criança, sua mãe frequentava um terreiro de candomblé e, consequentemente, Vermelho e seus irmãos também o frequentevam, tendo contato com várias pessoas da comunidade LGBT que encontravam no local. Após cerca de dez anos como candomblecista, a mãe de Vermelho, juntamente com seu atual padrasto passaram a frequentar a igreja evangélica, posteriormente seguida por sua filha e, logo após, vermelho que, na época, tinha 12 anos.

Após "aceitar Jesus", Vermelho relata que passou 08 anos vivendo recluso, pois ainda não aceitava a própria sexualidade e tentava esconder quem realmente era, até que começou a se desvincular da igreja e, apesar do vínculo de sua mãe, esta nunca o forçou a frequentar os cultos. Aos 19 anos, Vermelho passa a lidar melhor com sua sexualidade e a conhecer pessoas que já haviam assumido publicamente a sua orientação sexual, começando assim a acreditar que estava chegando a sua vez de passar pelo mesmo processo, interrompendo totalmente o vínculo com a igreja.

Aos 20 anos Vermelho se permite incluir ainda mais no meio LGBT através de aplicativos de relacionamento, tendo sua primeira experiência com uma pessoa do mesmo sexo e passando a consumir mais coisas associadas a esta população, até que relata sentir a necessidade de contar sobre sua orientação para a sua mãe. Então, mesmo com medo de qual seria sua reação, Vermelho diz a ela que precisava falar sobre algo que o incomodava e que, como se já soubesse do que se tratava, sua mãe diz que poderiam conversar em outra ocasião.

Passado algum tempo, sua mãe o chama para conversar e, nesta ocasião, tomado por um misto de medo e vergonha, Vermelho fala sobre ser gay, sua necessidade de se autodescobrir e parar de se esconder atrás da igreja. No primeiro momento, a reação de sua mãe foi falar sobre a bíblia, o que ela diz sobre isso e qual seu ponto de vista em relação, mas, após algum tempo de conversa, estando ambos em lágrimas, sua mãe diz que o ama, que respeitava sua "escolha" e jamais viraria as costas para ele.

Vermelho diz que o processo de assunção da sua sexualidade não interferiu na sua relação com familiares, apenas que no ínicio, houve um período de adaptação e construção de um respeito mútuo entre ele e sua mãe e que, com a irmã e o irmão, nada mudou. Ainda relata que, caso sua mãe tivesse uma opinião negativa, esta influenciaria e teria um peso muito grande na sua vida.

Quanto aos obstáculos para sua assunção, Vermelho acredita que eles foram, em sua maioria, externos. Citando que durante a infância e adolescência sofria muito bullying na escola devido a ser uma criança introspectiva e afeminada, e que, após contar para sua família, ainda havia o medo do julgamento por pessoas que não faziam parte do seu círculo familiar, mas a reação da sua mãe foi o que deu forças para não dar relevância a comentários de pessoas externas.

Ao final, Vermelho diz que, após assunção da sexulidade, não perdeu vínculo com amigos e que se sente privilégiado pelo núcleo familiar em que está inserido, ainda mais por ter amigos que passaram ou passam por um processo de aceitação bastante doloroso, não tendo familiares ou amigos que apoiam ou respeitam sua orientação sexual.

\section{Discussão}

Seguindo-se da apreciação dos relatos, identificaram-se em comum as adversidades em se reconhecer gay, medos quanto à reação da família perante a revelação da orientação sexual, isolamento devido ao medo e empoderamento para enfrentamento de adversas situações após a revelação.

\section{Descoberta da orientação sexual}

Percebe-se que a autodescoberta da orientação pode ocorrer de formas e em períodos muito diferentes, ficando evidenciado através de falas como: "É eu descobri a minha orientação por volta dos, por volta não, com 14 anos para ser bem exato" (Azul) e "Acho que desde pequeno eu já sabia, eu acho que com uns 07 anos eu já sabia que eu não era hétero" 
(Vermelho).

Constatou-se a dificuldade dos individuos no processo de autoaceitação revelado nas seguintes falas: “eu não posso é ser assim, não posso me sentir assim porque eu vou pro inferno, e é errado...” (Azul) e “...durante a minha vida toda, até os 19 anos eu ainda ia pra igreja com ela (mãe) e tals, ai meio que tentava esconder isso (...) dos outros e até de mim mesmo" (Vermelho).

O medo de que a sua orientação venha a público e as consequências disso são muito presentes em ambos participantes:

Antes eu me sentia, é , eu sentia medo de que qualquer coisa que eu dissesse fosse revelar isso (...) sempre sofri essa pressão, até por meio, até por minha mãe também, ela sempre admitiu que não queria um filho gay (Azul).

Eu passei esses oito anos da minha vida no evangelho é... recluso sabe?! Tipo... me escondendo, escondendo quem eu era, todo o meu ser (...) com medo, porque minha mãe sempre foi bruta sabe?! Tipo nervosa e tal. (...) Mas tipo, eu tinha medo, bastante medo (...) que sei lá... ela não me aceitasse, que ela me colocasse pra fora e tal ... (Vermelho).

\section{Revelação da orientação sexual para família}

As suposições pessoais quanto as possíveis reações da família fizeram com que um dos participantes cogitasse assumir uma relação heterossexual para evitar constrangimentos:

... teve um momento, numa conversa com uma amiga minha, que eu disse 'Velho eu não posso conversar isso com minha mãe. Ela não pode saber isso, eu vou sei lá namorar e casar com uma menina, porque ela não merece esse desgosto e tudo mais'. (...) ai eu fui vendo que a partir desse momento (...) isso não era possível. Eu não conseguia gostar, não conseguia me atrair por meninas e isso me machucava (Azul).

Em decorrência do medo, o momento em que se decide contar para família foi identificado como um dos mais aguardados e que causa mais expectativas e tensão nos envolvidos:

(...) numa noite que eu cheguei (...) e falei 'mãe, olha a gente precisa conversar! Eu sou gay!' (...) ai nesse momento ela tava com o semblante normal, até um tanto feliz, mas assim que eu contei aquilo decaiu, sabe um olhar de decepção, é, só que não surpresa, ela não tava surpresa (Azul).

... eu precisava falar algo pra ela que tava me incomodando muito nos últimos meses (...) ela ficou um pouco assim, com medo sabe?! Ou ao mesmo tempo como se já soubesse o que era (...) aí eu peguei e falei que (...) eu não aguentava mais e tals.. e que eu precisava... sei lá me descobrir, ser eu de verdade. Então eu falei pra ela que eu era gay, que... era isso... que eu era o mesmo por... sempre fui o filho dela e continuaria sendo, mas que não dava pra mim mais essa vida de tipo.. ter que me esconder atrás da igreja (Vermelho).

Identificou-se que a reação da família ao saber da orientação sexual dos indivíduos é bastante pautada na religiosidade, mas, não necessariamente, reflete seu posicionamento: “(...) em uma outra noite ela chegou pra mim na sala e disse 'eu aceito porque não tem como né?!, só que assim eu acho que isso é coisa do demônio, é uma maldição de família e enfim eu não posso fazer nada', ai eu recebi aquilo e fiquei sem reação”" (Azul). 
... ela falou da Bíblia, falou do ponto de vista dela... o que a bíblia diz sobre isso... aí eu falei 'Sim, mas eu não tive escolha. Eu sou isso e... é isso'. Aí ela chorou bastante, eu também chorei e aí a gente se abraçou e ela olhou pra mim... nos meus olhos e eu acho que foi uma das primeiras que eu vi, tipo.. ela demonstrar o que sentia por mim ali, com palavras e pelo olhar dela também. Aí ela falou que me amava e que... isso não ia mudar a nossa relação e que ela taria ali pra tudo que eu precisasse (Vermelho).

A reação dos familiares demonstrou como seria a convivência a partir daquele momento e o que os mesmos poderiam esperar.

A relação com minha mãe que é com quem eu convívo, obviamente, não é das melhores porém não é a pior coisa do mundo, é aquela coisa ela no canto dela e eu no meu, as vezes a gente conversa as vezes não, mas não é algo, tipo a gente não troca farpas (Azul).

Então ela me respeita enquanto a isso, não impõe nada a mim e eu acho que é isso, mas... com relação a outros familiares tipo.. irmãos é... nada mudou pra mim... é basicamente a mesma coisa (Vermelho).

\section{Empoderamento Pessoal}

Após revelação da orientação sexual, ficou evidente que esse processo trouxe resultados positivos para os dois envolvidos:

Atualmente minha relação com todo mundo ta de boas, é como eu disse eu prefiro ficar na minha, porque tem muita ideia que não bate, escuto comentários que eu não gosto, que tenho que aprender a lidar sim, mas ta na boa, não exponho mais minhas ideias como antigamente a menos que peçam que eu exponha, eu não fico mas em reunião de família, eu acho que não me sinto mas bem (Azul).

A reação da minha mãe frente a mim, acho que isso me deu força, sabe?! Pra tipo, não me importar mais com o que o outro vai pensar sobre mim ou qualquer outra coisa assim (Vermelho).

O empoderamento pessoal se tornou evidente nas relações pessoais como um todo, deixando claro que a assunção da sexualidade para familia possibilitou que os mesmos se aceitassem como individuos comuns perante a sociedade, resultando em pessoas fortes diante de qualquer situação. Evidenciando-se nas falas:

Depois que eu revelei que era gay, que eu me assumir gay, ficou tudo bem melhor porque pelo menos com os meus amigos eu tenho mais proximidade, eu gosto de tá no meio e assim eu falo sobre tudo, eu falo de como eu sou e sempre me aceitaram de uma maneira muito legal, nunca viram como algo anormal, nunca chegaram pra mim e disseram putz que errado, que coisa feia, não, sempre me acolheram de um modo muito legal e enfim acho que isso ajudou bastante para eu poder ser eu, ser mais eu sabe, em qualquer lugar e é basicamente isso e antes de eu me revelar que era gay, eu era muito fechado ate pra falar sobre meus próprios sentimentos sobre o que se passava comigo (Azul).

Eu acho assim.. hoje em dia eu num... tipo não ligo de falar sobre isso entendeu?! Eu não ligo de falar sobre a minha orientação sexual com ninguém, não tenho medo de falar “ah, eu sou gay e tals” ou algo do gênero, não tenho, mas no início era bastante complicado... tinha toda aquela questão de... do medo de ser julgado ou algo do gênero pelo 
outro, mas hoje em dia eu não mais. Acho que... a reação da minha mãe frente a mim acho que isso me deu força, sabe?! (Vermelho).

\section{Considerações Finais}

Devido à falta de compreensão acerca de sua orientação sexual, a população cis gay vivencia o preconceito e inúmeras diferenças sociais há gerações, tornando-se esta uma temática relevante a ser estudada para trazer respostas e respeito perante a sociedade para essa população.

Por se tratar de um estudo que lida com questões muito pessoais e que, muitas vezes, não são compartilhadas com facilidade, a principal limitação deste trabalho foi encontrar pessoas que aceitassem relatar suas histórias. As dificuldades foram potencializadas devido à pandemia por COVID-19, que impossibilitou um contato mais afetuoso com os participantes, visto que, a video conferência se configura como um ambiente mais sério, causando certa frieza e desafeição entre pesquisadores e pesquisados, resultando num baixo quantitativo de participantes.

O presente estudo se mostrou fundamental para embasar discussões relacionadas à influência das reações e vínculos familiares no processo de descoberta da orientação sexual do indivíduo, bem como, no seu comportamento perante a família e a sociedade. Este trabalho não teve por objetivo, nem considera como fundamental que homens gays optem por passar pelo processo de coming out, sendo este critério de inclusão utilizado apenas para que fosse possível identificar suas repercussões no seio familiar. O critério de inclusão de pessoas maiores de 18 anos trouxe consigo o fato de que os familiares destes indvíduos tenham tido uma base social muito conservadora e, consequentemente, imponham isso aos seus filhos.

Tornou-se evidente a necessidade de gerar produções e discussões, visando à compreensão do conteúdo pela população estudada e aqueles que lhes cercam, despertando o interesse de aprofundamento quanto a vivencias dos sujeitos, motivando-nos a busca da produção de evidências científicas para ressaltar a importância desta temática na formação pessoal, social e profissional, independente de qual seja a área do conhecimento.

Portanto, com base nos fatos mencionados anteriormente, evidencia-se a importância do presente estudo gerar a realização de mais pesquisas, com o escopo de ampliar ainda mais o conhecimento acerca do coming out de gays.

\section{Referências}

Bourdieu, P. (2010). A dominação masculina. Trad. de Maria Helena Kühner. (7a ed.), Bertrand Brasil.

Brasil. (2013). Projeto de Lei n ${ }^{\circ}$ 6.583/2013 - Câmara dos Deputados. http://www.camara.gov.br/proposicoesWeb/prop_mostrarintegra?codteor=1159761 \&filename $=P L+6583 / 2013$.

Carrara, S. \& Helborn, M. L. (2009). Gênero e diversidade na escola: formação de professoras/es em Gênero, Orientação Sexual e Relações Étnico-Raciais. Livro de conteúdo. Versão 2009. CEPESC; SPM.

Dewes, J. O. (2013). Amostragem em bola de neve e respondent-driven sampling: uma descrição dos métodos. Monografia (Bacharelado em Estatistica). Universidade Federal do Rio grande do Sul. https://www.lume.ufrgs.br > bitstream > handle.

Dias, M. B. (2000). União Homossexual, o Preconceito e a Justiça. Livraria do Advogado.

Foucault, M. (1998). História da sexualidade I: A vontade de saber, Tradução de Maria Thereza da Costa Albuquerque e J. A. Guilhon Albuquerque, Edições Graal.

Esperanca, A., Silva, I. R. da. \& Neves, A. L. M das. (2015). Significados e sentidos sobre homossexualidade entre docentes: uma análise sócio-histórica. Temas psicol., 23, 739-749. http://pepsic.bvsalud.org/scielo.php?script=sci_arttext\&pid=S1413-389X2015000300017\&lng=pt\&nrm=iso.

Estrela, C. (2018). Metodologia Científica: Ciência, Ensino, Pesquisa. Editora Artes Médicas.

Koche, J. C. (2011). Fundamentos de metodologia científica. Vozes. http://www.brunovivas.com/wp-content/uploads/sites/10/2018/07/K\%C3\%B6cheJos\%C3\%A9-Carlos0D0AFundamentos-de-metodologia-cient\%C3\%ADfica-_teoria-da0D0Aci\%C3\%AAncia-e-inicia\%C3\%A7\%C3\%A3o-\%C3\%A0pesquisa.pdfhttps://repositorio.ufsm.br/bitstream/handle/1/15824/Lic_Computacao_Metodologia-Pesquisa-Cientifica.pdf?sequence=1

Ludke, M. \& Andre, M. E . D. A. (2013). Pesquisas em educação: uma abordagem qualitativa. E.P.U. 
Research, Society and Development, v. 10, n. 8, e47910817826, 2021

(CC BY 4.0) | ISSN 2525-3409 | DOI: http://dx.doi.org/10.33448/rsd-v10i8.17826

Maffesoli, M. Homossocialidade: Da identidade às identificações. Bagoas: Estudos Gays: Gêneros E Sexualidades, 1(1), 15-25. (2007). https://periodicos.ufrn.br/bagoas/article/view/2250.

Martins, F., Romão, L., Lindner, L. \& Reis. T. (2010). Manual de Comunicação LGBT. Ajir Artes Gráficas.

Miskolci, R. (2015). "Discreto e fora do meio" - Notas sobre a visibilidade sexual contemporânea. Cadernos Pagu, (44), 61-90. http://www.scielo.br/scielo.php?pid=S0104-83332015000100061\&script=sci_abstract\&tlng=pt.

Mota. T. de S., Rocha, R. F. \& Mota, G. B. C. (2011). Família - Considerações gerais e historicidade no âmbito jurídico. In: Âmbito Jurídico, Rio Grande, XIV, n. 84, jan. https://jus.com.br/artigos/32837/o-atual-conceito-de-constituicao-de-familia-e-a-sua-positivacao-no-ordenamento-juridico-brasileiro.

Nascimento, G. C. M. (2018). A perspectiva familiar diante da revelação da orientação homossexual de jovens e adultos. 2018. 121f. Dissertação (Mestrado em Psicologia) - Programa de Pós-Graduação em Psicologia, Universidade Federal do Triângulo Mineiro, Uberaba. http://bdtd.uftm.edu.br/handle/tede/547.

Nolte, D.L. \& Harris, R. (2005). Os adolescentes aprendem o que vivenciam. Sextante.

Pereira A. S. et al. (2018). Metodologia da pesquisa científica. UFSM.

Toneli, M. J. F. (2012). Sexualidade, gênero e gerações: continuando o debate. In Jacó-Vilela, \& Sato, L., orgs. Diálogos em psicologia social. Centro Edelstein de Pesquisas Sociais, 147-167.

Zagury, T. (2002). O adolescente por ele mesmo. (13a ed,), Record.

Yin, R.K. (2015). O estudo de caso. Bookman. 